Received: November 21, 2017

\title{
Study on College English Teaching Interaction and Teaching Practice Based on Connectivism from the Neurocognitive Perspective
}

\author{
Liying $\mathrm{Cao}^{1}$ \\ Hunan Institute of Engineering
}

\begin{abstract}
Neurocognitive science aims at clarifying the brain basis of psychological activities, especially human psychological activities, thus revealing the relationship between psychology and brain. The large-scale open network course (cMOOC) based on connectivism from the neurocognitive perspective, presents a good interpretation of the core of the connectivism using Web2.0 technology. Particularly, the English course features good interaction between teachers and students on class, which can provide a good reference. This study analyzes the status quo of English teaching interaction in colleges by means of questionnaire survey and interview, uses the connectivism to propose some suggestions on how to improve teaching interaction with the help of cMOOC model and Web2.0 technology from the neurocognitive perspective, and analyzes the significance of English teaching interaction and the present situation of English teaching interaction in colleges in China. Finally, the experiment verifies the effectiveness of this method in improving student English academic performance.
\end{abstract}

\section{Keywords}

English Teaching Interaction $•$ Teaching Practice $•$ Connectivism $•$ Neurocognitive Perspective

${ }^{1}$ Correspondence to: Liying Cao, International Education College, Hunan Institute of Engineering, Xiangtan 411104, China. Email: 14007@hnie.edu.cn

Citation: Cao, L. Y. (2018). Study on College English Teaching Interaction and Teaching Practice Based on Connectivism from the Neurocognitive Perspective. Educational Sciences: Theory \& Practice, 18(5), 2338-2346. http://dx.doi.org/10.12738/estp.2018.5.132 
On a class in colleges, one often sees a teaching talking tediously on the podium, while students are sitting idly underneath. Resonance and communication are absent between the teacher and the student. The knowledge is transmitted linearly from textbook to teacher, then to student and finally is lost. This cycle goes on and on (Agostinho et al., 2015; Dyment \& Timothy, 2014; Cox \& Sanz, 2015), frittering away a large amount of precious time. In addition to review and textual research before examination, college students rarely "ruminate" or review the knowledge they have learned in class but threw it aside after class, as if the knowledge always belongs to the classroom (Shafiei, Hussein \& Guru, 2017). Why the students who have just experienced the baptism of college entrance examination have suddenly lost their thirst for knowledge facing the vast knowledge sea. The three pressures of effective education in the information age are shown in Figure 1.

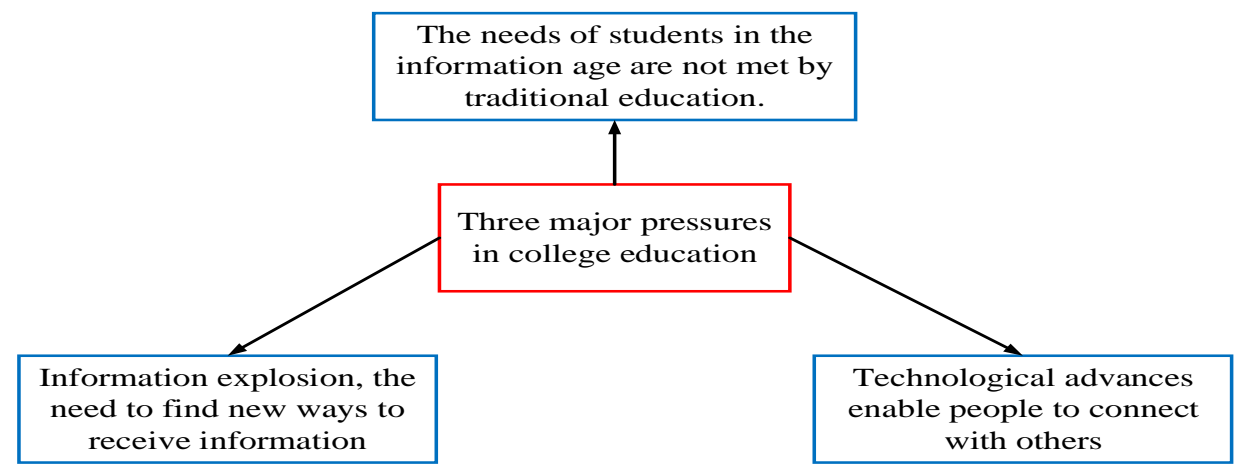

Figure 1. The pressure of efficient education in the information age.

The so-called half-life of knowledge refers to the time span from the time that certain knowledge is learnt to its obsolescence (Gotwals \& Birmingham, 2016). In today's information age, there are three factors affecting the production and dissemination of information and any of these three factors may have subversive effects on today's traditional higher education (Muhle-Karbe, Duncan, Baene, Mitchell \& Brass, 2016). They are as follows. The learning needs of millions of people cannot be fully satisfied under the traditional teaching mode; the information explosion makes it urgent to find a way to absorb, manage and classify massive information; Today's advanced technology enables learners to fully communicate with each other and establish their own knowledge network. This new change is bound to put forward new requirements on the ability of teaching interaction in colleges (Tardif, Doudin \& Meylan, 2015). The changes that have taken place in the media are confirming Simmons's view that people are already free to exchange information and learn new knowledge in blogs, microblogs, social networking sites and video sites. The flow of information is no longer unidirectional, but bidirectional even multi-directional (Mulvey, Chiu, Ghosh \& Bell, 2016). Because of these new changes, traditional learning theories, such as cognitive theory, behavior theory and construction theory, can no longer meet people's needs. 


\section{Cognitive neuroscience}

\section{Development of cognitive neuroscience}

Neurocognitive science aims at clarifying the brain basis of psychological activities, especially human psychological activities, thus revealing the relationship between psychology and brain. Neurocognitive science was born at the end of the 20th century (Owings et al, 2006). However, scientists have begun to study the relationship between psychology and brain as early as the beginning of the 19th century. Later, phrenology, work theorem and neuron theory were proposed, which laid a solid foundation for the birth of neurocognitive science. The schematic diagram of thinking in the application of neurocognitive science is shown in Figure 2.

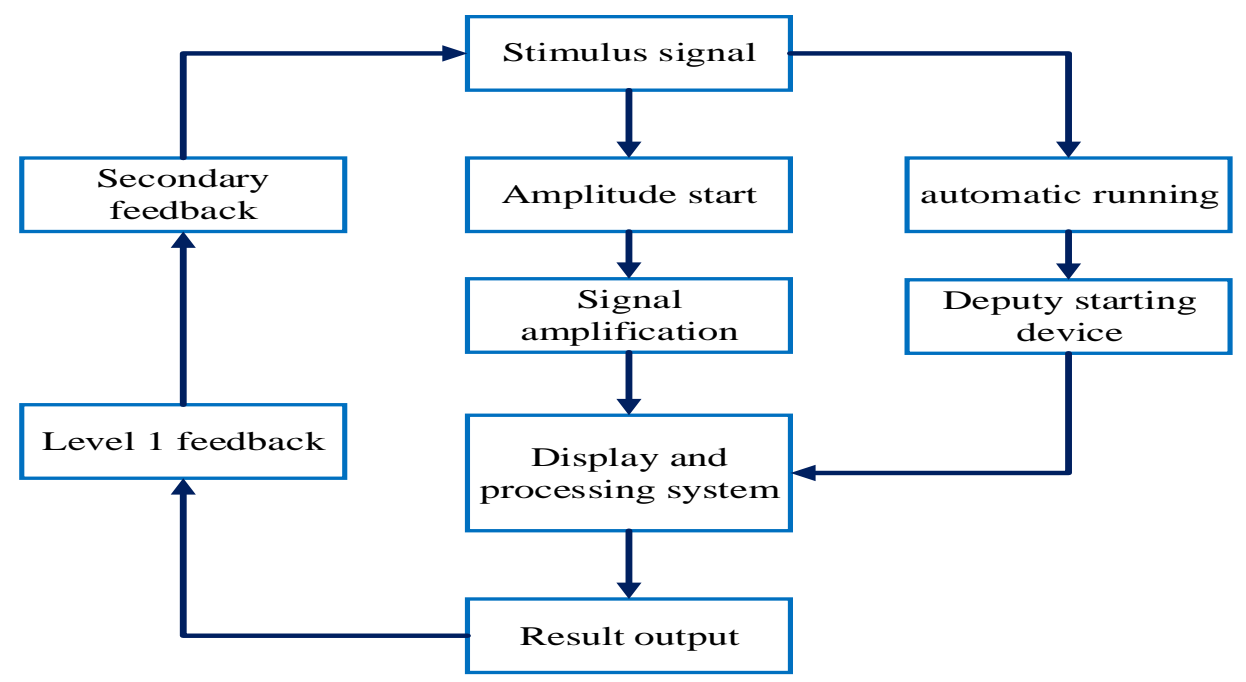

Figure 2. Schematic diagram of thinking in the application of neurocognitive science.

\section{Cognitive neural network model}

The traditional pattern recognition diagnosis method, Bayesian theory, is used to illustrate how neural network is applied to college education (Osterholt \& Dennis, 2014). Assuming that the conditional probability density function of the pattern sample to be identified is a normal distribution, it is expressed as follows,

$$
f\left(\frac{X}{w_{i}}\right)=\frac{1}{2^{\frac{n}{2}} \sqrt{\left|C_{i}\right|}} \exp ^{\left(-\frac{1}{2}\left(X-m_{i}\right)^{T} C_{i}^{-1}\left(X-m_{i}\right)\right)}
$$

Where, $\mathrm{X}=\left[x_{1}, x_{2}, \cdots, x_{n}\right]^{T}$ is the input pattern sample, $w_{i}$ is the class i pattern set, and $m_{i}$ is the mean vector of i-th pattern class. $C_{i}$ is the covariance matrix of the i-th pattern class? 
If the following Bayesian rule is satisfied, then $\mathrm{X} \in w_{i}$.

$$
\frac{f\left(\frac{X}{w_{i}}\right) f\left(w_{i}\right)}{f(X)}=\max _{j}\left(\frac{f\left(\frac{X}{w_{j}}\right) f\left(w_{j}\right)}{f(X)}\right)
$$

Where, $\mathrm{f}\left(w_{i}\right)$ is the prior probability of pattern class $w_{i}$, and $\mathrm{f}(\mathrm{x})$ is the probability density function of sample X.

Assuming that the prior probabilities of all pattern samples are the same, take the natural logarithm for Formula (2), then,

$$
L(i)=\min _{j}(L(j))
$$

Where, $L$ ( $\mathrm{i}$ ) is

$$
\begin{aligned}
L(i) & =\left(X-m_{i}\right)^{T} C_{i}^{-1}\left(X-m_{i}\right)+\ln \left|C_{i}\right| \\
& =\sum_{j} \sum_{k} r_{i}\left(x(k)-m_{i}(j)\right)\left(x(k)-m_{i}(j)\right)+\ln \left|C_{i}\right|
\end{aligned}
$$

Then the structure corresponding to Formula (4) can be implemented by a neural network that first finds the product and then sums. Assuming that the network input and output of the i-th neuron are:

$$
\begin{aligned}
& n e t(i)=\theta(i)+\sum_{j} W_{1}(i, j) x(j)+\sum_{j} \sum_{k} W_{2}(i, j, k) x(j) x(k) \\
& \text { out }(i)=\frac{1}{1+\exp [-n e t(i)]}
\end{aligned}
$$

Where,

$$
\begin{aligned}
& \theta(i)=\sum_{j} \sum_{k} r_{i}(j, \mathrm{k}) m_{i}(k)+\ln \left|C_{i}\right| \\
& W_{1}(i, j)=-2 \sum_{k} r_{i}(j, k) \cdot m_{i}(k) \\
& W_{2}(i, j, k)=r_{i}(j, k)
\end{aligned}
$$

The above formula shows that one component of the covariance matrix in the pattern class can be represented by a weight of the neural network, that is to say, the traditional Bayesian theory can be realized by the neural network in the college teaching interaction (Mulvey, Chiu, Ghosh \& Bell, 2016). In general, the pattern distribution is irregular, and various nonlinear segmentation planes are formed in the pattern space. 
$\overline{\text { Although clustering method can realize any complex decision plane, it still has a certain gap compared with }}$ neural network in realizing this task.

\section{Basic concept of relevance}

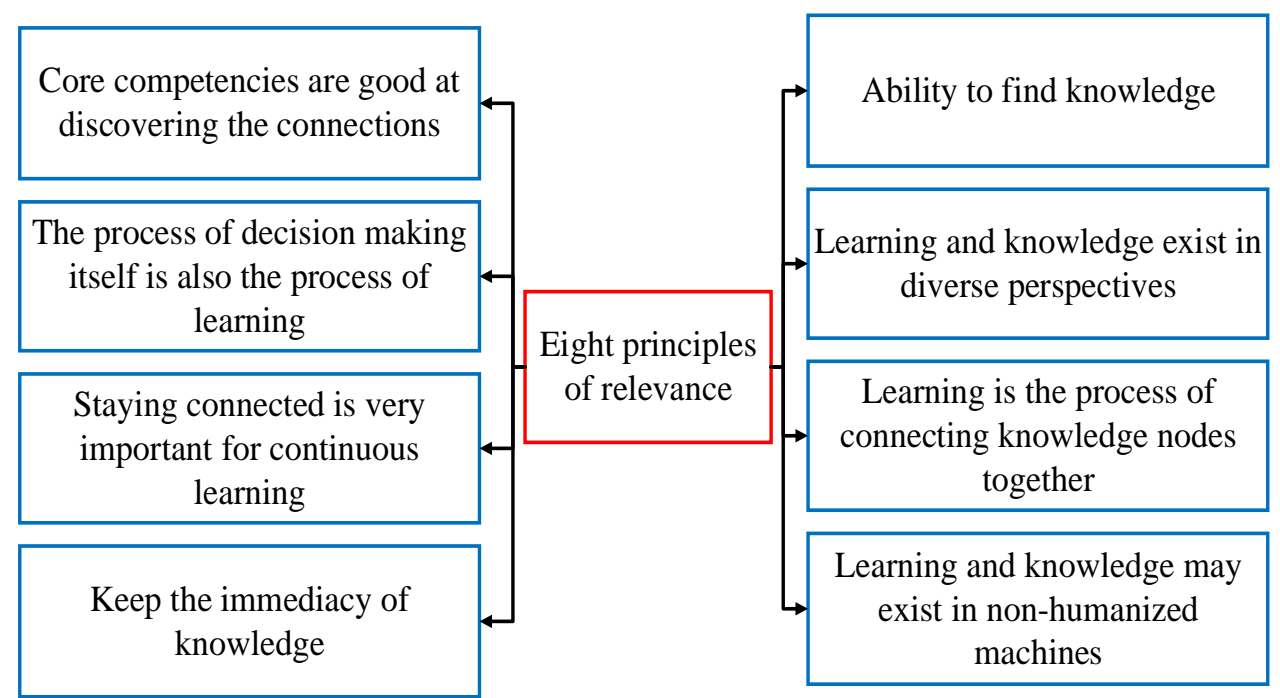

Figure 3. Eight principles of relevance.

\section{Relevance thinking}

From the beginning, connectivism is closely related to the network organization. In this network, each person is a node, and some nodes are called "hub nodes", that is, the nodes with very high connectivity in the network. For example, in human society, a small number of people who know each other have a large number of connecters, such as college teachers. In the network with hub nodes, the structure of the network is dominated by the hub nodes, so the network presents small-world effect. In fact, the hub node has a connection with a very large number of nodes, so that shortcuts are established between any two nodes in the system. The eight principles of connectivism are shown in Figure 3.

Knowledge is not static, nor passively accepted by people, but constantly communicates with its creators in a reflective and critical way. In the past, this process was slow. The link knowledge flow is shown in Figure 4.

Knowledge begins to spread from individuals, groups or organizations, which has undergone five processes, including collaborative creation, dissemination, communication, personalization, and practice. 


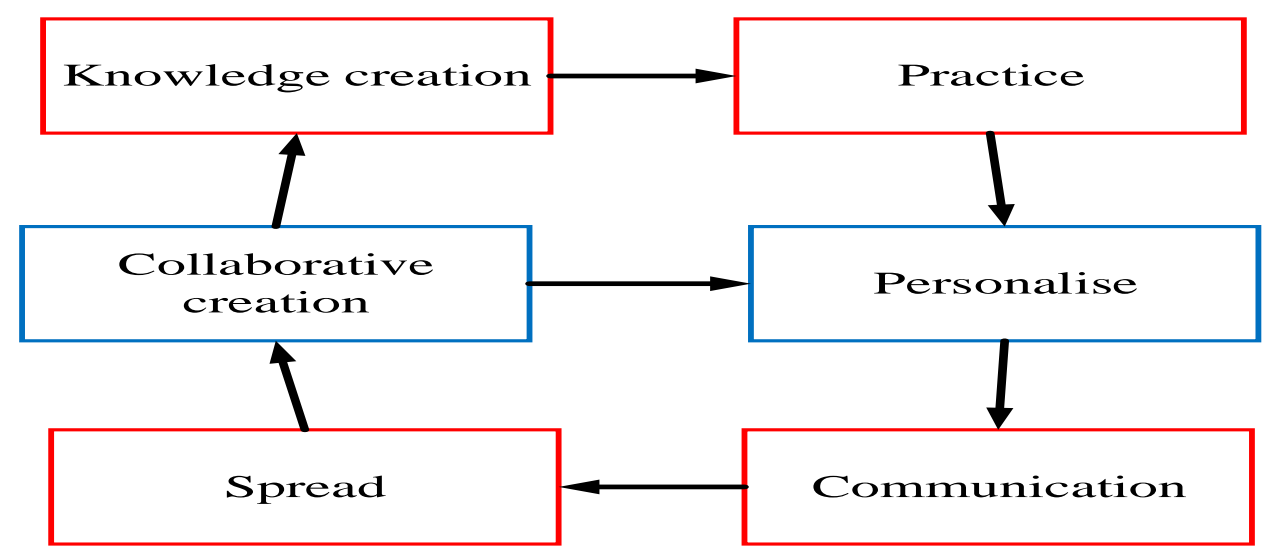

Figure 4. Linked knowledge flow.

\section{Introduction of Relevance in the Teaching Interaction and Teaching Practice in Colleges and Universities}

\section{Introduction of the Connotation of Relevance Theory}

Connectivism holds that knowledge does not exist in the textbooks in a closed and static manner, but is attached in the network in an open and dynamic manner. Thus, it is very important to connect with the learning network. Since knowledge in the network is constantly being updated, staying connected to it is the only way for us to get the most up-to-date knowledge at any time. Connectivism believes that the process of learning is the process of learning the establishment of the network, that is, the process by which people connect with the learning community. The establishment of the learning network must involve the multi-directional interaction with others, which is also the reason why connectivism emphasizes and promotes communication. The evaluation index system of college teachers' teaching effectiveness is shown in Table 1.

Table 1

Study on the Evaluation Index System of Teaching Efficiency of College Teachers

\begin{tabular}{ll}
\hline Dimensions & \multicolumn{1}{c}{ First-level indicators } \\
\hline & Course teaching \\
Teaching performance & Student training \\
& Teaching achievement \\
Research performance & Research funding \\
Management service performance & Research achievements \\
\hline
\end{tabular}

\section{Introduction of Relevance Teaching Practice}

The teaching practice of connectivism mainly refers to the application of cMOOC and Web2.0 technique based on connectivism in teaching. As can be seen from the previous introduction, the main feature of cMOOC 
is decentralization, wherein knowledge is learnt by establishing a learning network and interacting with others, which provides a good inspiration for the current status of teaching interaction in Chinese colleges. In order to make the teaching interaction mode of $\mathrm{CMOOC}$ more operable, the author tries to propose a preliminary solution to the college teaching interaction by combining the teaching steps of cMOOC and the Web2.0 technique which may be promoted in China.

Knowledge accumulation before class Students do not need to know much about the content before class, but they shall be motivated to actively interact and build a learning network. If this goal is achieved, so will be the goal for knowledge accumulation before class. Wiki plays the role of knowledge point construction throughout the process. Specifically, teachers can create interfaces (entry terms) related to teaching knowledge on Wiki sites such as Wikipedia, Baidu Encyclopedia or Concept board, and invite all students to construct the entry from scratch by collecting data.

Interaction on class There is no traditional class interaction in $\mathrm{cMOOC}$, which is the biggest difference between cMOOC and college teaching, and it is also the central link of teaching interaction. In this process, without the assistance of Web2.0 tools, the interactive concept of connectivism and the extracurricular preparation effect become the key factors affecting class interaction.

Consolidation of interaction after class After extensive reading of the student's blog feedback, the teacher intercepts representative views or articles therein, and then pushes them to all students through the RSS function, and attaches leading questions, relevant new materials to the push information, with a purpose to engage students in discussion and interaction. The discussion platform may be a social software platform such as QQ and Wechat. Since the student already has a deep understanding of the teaching content at this time, the discussion is for the exchanging ideas to strengthen the connection between nodes. The different components of neurocognition are shown in Table 2 .

Table 2

Different Components of Cognitive Nerves

\begin{tabular}{lcc}
\hline \multicolumn{2}{c}{ Component } \\
\hline & $F_{1}$ & $F_{2}$ \\
$X_{1}$ & 0.898 & 0.364 \\
$X_{2}$ & 0.859 & 0.419 \\
$X_{3}$ & 0.853 & 0.412 \\
$X_{4}$ & 0.898 & 0.357 \\
$X_{5}$ & 0.887 & 0.331 \\
$X_{6}$ & 0.383 & 0.923 \\
\hline
\end{tabular}

\section{Performance analysis}

The method proposed in this study is used for the contrast experiment on the students in the experimental class. Through long-term training and learning, this study analyzes the effect of the neurocognition-based teaching interaction and teaching practice method in improving students' performance. As can be seen from Figure 5, the proposed method can effectively reduce the error rate of students, and the average error rate of students will continue to decrease with the increase of the time of using the proposed algorithm, until finally reaches the lowest level. 


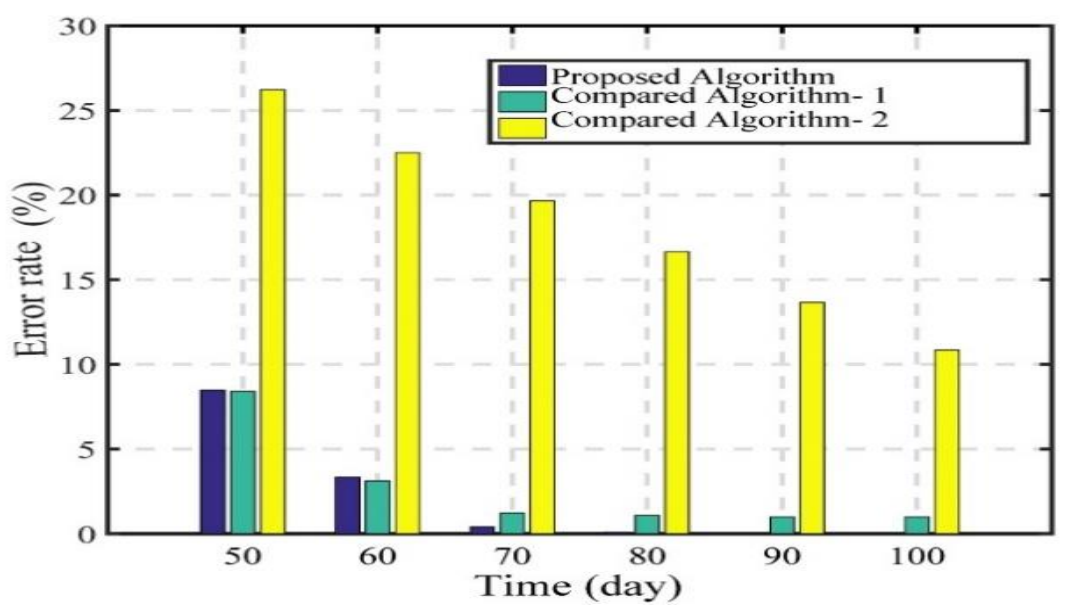

Figure 5. Performance of the algorithm in this paper.

\section{Conclusion}

This study integrates and analyzes connectivism and English teaching interaction. In view of the problems existing in English teaching interaction at present, this study proposes concrete and feasible measures for improving the English teaching interaction before, during and after the class, and constructs the learning network of students, with references to cMOOC's teaching interaction ideas and Web2.0 technique. In effective English teaching interaction, students are lack of reading skills, as teachers usually ignore the importance for students to the construct knowledge, thus hindering the exertion of students learning initiative. The connectivism learning theory emphasizes the student as the main body. The main goal of English reading teaching in university is to improve students' reading consciousness. Through the case study of digital teaching, this study proposes the four steps of guiding junior high school teaching using connectivism learning theory, and explores teaching based on connectivism, which has greatly improved the English teaching effect.

\section{References}

Agostinho, S., Tindall-Ford, S., Ginns, P., Howard, S. J., Leahy, W., \& Paas, F. (2015). Giving learning a helping hand: Finger tracing of temperature graphs on an iPad. Educational Psychology Review, 27(3), 427443. https://doi.org/10.1007/s10648-015-9315-5

Dyment, J., \& Timothy, O. C. (2014). When the ink runs dry: implications for theory and practice when educators stop keeping reflective journals. Innovative Higher Education, 39(5), 417-429. http://dx.doi. org/10.1007/s10755-014-9291-6

Cox, J. G., \& Sanz, C. (2015). Deconstructing PI for the ages: Explicit instruction vs. practice in young and older adult bilinguals. International Review of Applied Linguistics in Language Teaching, 53(2), 225-248. http://dx.doi. org/10.1515/iral-2015-0011 
Cao / Study on College English Teaching Interaction and Teaching Practice Based on Connectivism from...

Shafiei, S. B., Hussein, A. A., \& Guru, K. A. (2017). Cognitive learning and its future in urology: surgical skills teaching and assessment. Current Opinion in Urology, 27(4), 342-347. http://dx.doi. org/10.1097/MOU.0000000000000408

Gotwals, A. W., \& Birmingham, D. (2016). Eliciting, identifying, interpreting, and responding to students' ideas: Teacher candidates' growth in formative assessment practices. Research in Science Education, 46(3), 365-388. http://dx.doi. org/10.1007/s11165-015-9461-2

Muhle-Karbe, P. S., Duncan, J., Baene, D. W., Mitchell, D. J., \& Brass, M. (2016). Neural coding for instruction-based task sets in human frontoparietal and visual cortex. Cerebral Cortex, 27(3), 1891-1905. http://dx.doi. org/10.1093/cercor/bhw032

Tardif, E., Doudin, P. A., \& Meylan, N. (2015). Neuromyths among teachers and student teachers. Mind, brain, and Education, 9(1), 50-59. http://dx.doi. org/10.1111/mbe.12070

Mulvey, B. K., Chiu, J. L., Ghosh, R., \& Bell, R. L. (2016). Special education teachers' nature of science instructional experiences. Journal of Research in Science Teaching, 53(4), 554-578. http://dx.doi. org/10.1002/tea.21311

Owings, W. A., Kaplan, L. S., Nunnery, J., Marzano, R., Myran, S., \& Blackburn, D. (2006). Teacher quality and troops to teachers: A national study with implications for principals. Nassp Bulletin, 90(2), 102-131. http://dx.doi. org/10.1177/0192636506289023

Osterholt, D. A., \& Dennis, S. L. (2014). Assessing and addressing student barriers: Implications for today's college classroom. About Campus, 18(6), 1. http://dx.doi. org/10.1002/abc.21140 